\title{
Effect of short-term prewarming on body temperature in arthroscopic shoulder surgery
}

\section{Kwang-seob Shin, Guie Yong Lee, Eun Hee Chun, Youn Jin Kim, and Won Joong Kim}

Revised August 10, 2017

Accepted August 11, 2017

\author{
Corresponding author \\ Guie Yong Lee, M.D., Ph.D. \\ Department of Anesthesiology \\ and Pain Medicine, Ewha Womans \\ University School of Medicine, 1071, \\ Anyangcheon-ro, Yangcheon-gu, \\ Seoul 07985, Korea \\ Tel: 82-2-2650-5285 \\ Fax: 82-2-2655-2924 \\ E-mail: Igyanes@ewha.ac.kr
}

Department of Anesthesiology and Pain Medicine, Ewha Womans University School of Medicine, Seoul, Korea

Background: Hypothermia $\left(<36^{\circ} \mathrm{C}\right)$ is common during arthroscopic shoulder surgery. It is known that 30 to 60 minutes of prewarming can prevent perioperative hypothermia by decreasing body heat redistribution. However, the effect of short-term prewarming (less than 30 minutes) on body temperature in such surgery has not been reported yet. Therefore, the aim of this prospective study was to investigate the effect of short-term prewarming for less than 30 minutes using forced-air warming device on body temperature during interscalene brachial plexus block (ISBPB) procedure in arthroscopic shoulder surgery before general anesthesia.

Methods: We randomly assigned patients scheduled for arthroscopic shoulder surgery to receive either cotton blanket (not pre-warmed, group $C, n=26$ ) or forced-air warming device (pre-warmed, group $F, n=26$ ). Temperature was recorded every 15 minutes from entering the operating room until leaving post-anesthetic care unit (PACU). Shivering and thermal comfort scale were evaluated during their stay in the PACU.

Results: There were significant differences in body temperature between group $\mathrm{C}$ and group $\mathrm{F}$ from 30 minutes after induction of general anesthesia to 30 minutes after arrival in the PACU $(P<0.05)$. The median duration of prewarming in group $F$ was 14 min (range: 9-23 min). There was no significant difference in thermal comfort scale or shivering between the two groups in PACU.

Conclusions: Our results showed that short-term prewarming using a forced-air warming device during ISBPB in arthroscopic shoulder surgery had beneficial effect on perioperative hypothermia.

Key Words: Arthroscopic shoulder surgery, Perioperative hypothermia, Prewarming.

\section{INTRODUCTION}

Hypothermia is defined when the core temperature is lower than $36^{\circ} \mathrm{C}$. Patients undergoing surgery is prone to hypothermia because anesthetics can induce impairment of thermoregulation and cold environment. Perioperative hypothermia causes many problems such as blood clotting disorder [1], delayed wound healing and wound infection [2], cardiac complications [3], delayed recovery from anesthetics
[4], and thermal discomfort [5].

During arthroscopic shoulder surgery, a large amount of irrigation fluids stored at room temperature are used to improve the clarity of surgical field [6]. But a large amount of irrigation fluids stored at room temperature cause decrease in body temperature [7]. Previous studies have revealed that using warmed and humidified inspired gas [8] or warmed irrigation fluids is ineffective in preventing perioperative hypothermia $[6,7]$.

This is an Open Access article distributed under the terms of the Creative Commons Attribution Non-Commercial License (http://creativecommons.org/licenses/by-nc/4.0) which permits unrestricted non-commercial use, distribution, and reproduction in any medium, provided the original work is properly cited. 
Preventive methods include skin surface warming [9], warm and humidified circuit [10], and administering fluid or warming blood using specific devices [11]. Among these methods, forced-air warming is a very effective and safe method [12]. Forbes et al. [13] have recommended prewarming for 30 minutes before surgery to prevent perioperative hypothermia. Sessler et al. [14] have concluded that peripheral compartment heat content is increased in clinically important amounts within 30 minutes of warming. However, it is impractical to warm for more than 30 minutes due to thermal discomfort and congestion of pre-anesthetic care unit. The effect of short-term prewarming (less than 30 minutes) on body temperature during arthroscopic shoulder surgery has not reported yet.

Therefore, the aim of this prospective study was to investigate the effect of short-term prewarming using forced-air warming device on body temperature during interscalene brachial plexus block (ISBPB) in arthroscopic shoulder surgery before general anesthesia.

\section{MATERIALS AND METHODS}

This study was approved by the Institutional Review Board. Written informed consent was obtained from patients aged between 20 to 65 years. Patients with temperature above $37.5^{\circ} \mathrm{C}$ measured with a tympanic thermometer, history of malignant hyperthermia, or conversion to open shoulder surgery were excluded. Using random allocation software, patients were divided into two groups: 1) cotton blanket group (not pre-warmed, group C), patients were covered with warm cotton blanket stored in heating cabinet; and 2) forced-air warming group (pre-warmed, group F), patients were warmed using forced-air warming device (Bair Hugger Model 505, Arizant Healthcare Inc., USA) during the procedure of ISBPB for prewarming. The device had the highest setting of $43^{\circ} \mathrm{C}$.

Initial body temperature was measured with tympanic thermometer (ThermoScan IRT 6020, Braun, Germany) immediately after the patient was transferred to the operation room. Ambient temperature of the operation room was maintained at $21-23^{\circ} \mathrm{C}$. That of post-anesthetic care unit (PACU) was maintained at $23-25^{\circ} \mathrm{C}$. All patients were given $3 \mathrm{mg}$ of midazolam and $50 \mu \mathrm{g}$ of fentanyl intravenously before ISBPB procedure. ISBPB was performed using $12 \mathrm{ml}$ of
$0.5 \%$ ropivacaine containing $5 \mathrm{mg}$ of dexamethasone under ultrasound guidance. General anesthesia was induced using propofol $2 \mathrm{mg} / \mathrm{kg}$. Endotracheal tube was inserted after relaxation achieved by rocuronium $0.6 \mathrm{mg} / \mathrm{kg}$. General anesthesia was maintained using desflurane and $50 \%$ nitrous oxide in oxygen mixture based on bispectral index score between 40 and 60. Mechanical ventilation was controlled to maintain an end-tidal carbon dioxide concentration of 30-35 $\mathrm{mmHg}$. Esophageal thermometer (DeRoyal ${ }^{\circledR}$, DeRoyal Industries, Inc., USA) was inserted after intubation and temperature was continuously monitored and recorded every 15 minutes until the end of surgery. The lowest temperature during surgery was also recorded for evaluation of incidence and severity of hypothermia. All patients were positioned with the operative side facing upward. Patients in both groups were warmed with forced-air warming device below the level of xiphoid process intraoperatively. Additional $50 \mu \mathrm{g}$ of fentanyl was injected intravenously immediately before surgery. Irrigation fluids stored at room temperature $\left(21-23^{\circ} \mathrm{C}\right)$ in the operation room were used for surgery. On arrival at the PACU, postoperative temperature was measured with a tympanic thermometer to evaluate the incidence of hypothermia. Body temperature was measured every 15 minutes until leaving the PACU. Shivering and thermal comfort scale were recorded on arrival at PACU. Shivering was observed by blinded research assistant. Thermal comfort scale and numeric rating scale (NRS) pain score were recorded. Thermal comfort scale was recorded as 0 point for no cold, 1 point for moderate cold, and 2 points for unbearable cold. Pain score was evaluated using NRS ranging from 0 (no pain) to 10 (worst pain imaginable). If the patient felt cold or postoperative temperature was lower than $36^{\circ} \mathrm{C}$, forced-air warming was used in PACU.

The primary outcome was perioperative body temperature of the two groups. A sample size of 54 was required to detect a temperature difference of $0.5^{\circ} \mathrm{C}$ with a type $\mathrm{I}(\alpha)$ error of 0.05 and type II ( $\beta$ ) error 0.2 ( $80 \%$ power) considering $10 \%$ possible data loss. Continuous variables were analyzed using independent $t$ test while categorical variables were analyzed using Chi-square test or Fisher's exact test. Repeated measures analysis of variance with Bonferroni correction was used to compare changes in temperature between the two groups. All statistical analyses were performed using SPSS software (ver. 22.0; IBM Corp., USA). P values < 0.05 were considered statistically significant. 


\section{RESULTS}

For this study, 54 patients were enrolled initially. However, 2 patients were excluded due to delayed recovery from general anesthesia and conversion to open surgery (Fig. 1). There was no significant difference in age, operation room temperature, operation time, amount of intravenous fluid, volume of irrigation fluid, or duration of ISBPB procedure between the two groups (Table 1). The median duration of prewarming in group F was 14 min (range: 9-23 min).

The temperature on arrival at operation room did not differ significantly between the two groups $\left(36.6 \pm 0.4^{\circ} \mathrm{C}\right.$ in group $\mathrm{C}$ and $36.8 \pm 0.4^{\circ} \mathrm{C}$ in group $\mathrm{F}, \mathrm{P}=0.156$, Table 2 ). There were significant differences in body temperature between group $\mathrm{C}$ and group $\mathrm{F}$ from 30 minutes after induction of general anesthesia to 30 minutes after arrival in the PACU $(\mathrm{P}=0.039$ at 30 minutes after induction; $\mathrm{P}=0.003$ at 45 minutes after induction; $\mathrm{P}=0.001$ at 60 minutes after induction; $\mathrm{P}=0.004$ at the end of surgery; $\mathrm{P}<0.001$ on arrival at PACU; $\mathrm{P}<0.001$ at 30 minutes after admission to PACU, Fig. 2). The temperature on arrival at PACU for patients in group $\mathrm{C}$ was significantly lower than that for patients in group $\mathrm{F}\left(35.6 \pm 0.4^{\circ} \mathrm{C}\right.$ in group $\mathrm{C}$ and $36.1 \pm 0.4^{\circ} \mathrm{C}$ in group $\mathrm{F}, \mathrm{P}<0.001$, Table 2 ).

The incidence of hypothermia in the operation room was 96.2\% (25/26) in group C and 57.7\% (15/26) in group F ( $\mathrm{P}=$ 0.003 , Table 2). The incidence of hypothermia in PACU was $69.2 \%(18 / 26)$ in group $\mathrm{C}$ and $34.6 \%(9 / 26)$ in group $\mathrm{F}(\mathrm{P}=$ 0.026 , Table 2). Twenty percent of patients in F group and $40 \%$ of patients in group $\mathrm{C}$ showed moderate hypothermia intraoperatively. However, severities of hypothermia were not significantly different between the two groups ( $\mathrm{P}=0.239$, Table 2$)$. Percentages of patients who felt moderate cold were not significantly different between the two groups (26.9\% in group $\mathrm{C}$ and $19.2 \%$ in group $\mathrm{F}, \mathrm{P}=0.743$, Table 2 ). No shivering occurred in either group during stay in PACU. There was no significant difference in NRS pain score between the two groups.

\section{DISCUSSION}

In the present study, prewarming for less than 30 minutes

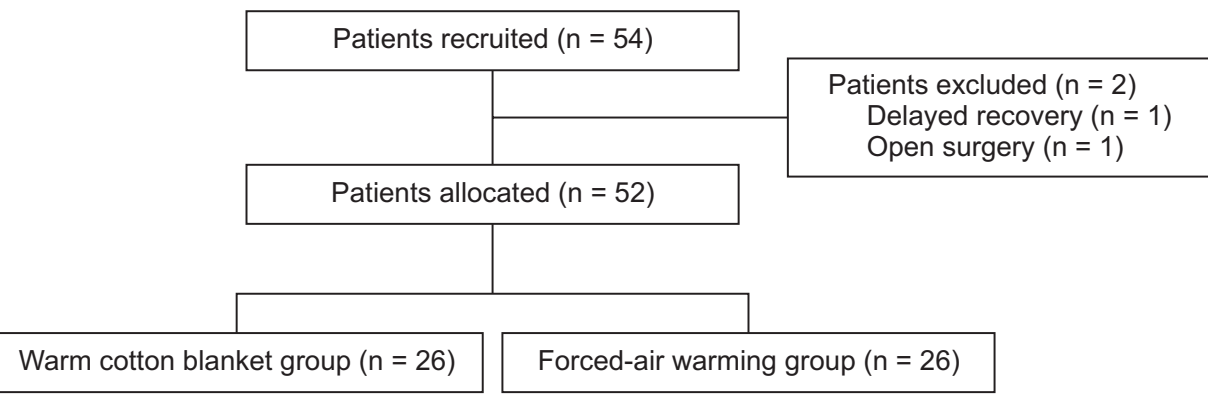

Fig. 1. Flowchart of inclusion/exclusion of patients in the study.

Table 1. Patient Characteristics and Perioperative Clinical Data

\begin{tabular}{lccc}
\hline \multicolumn{1}{c}{ Variable } & Group C $(\mathrm{n}=26)$ & Group F $(\mathrm{n}=26)$ & $\mathrm{P}$ value \\
\hline Age $(\mathrm{yr})$ & $52.8 \pm 10.3$ & $50.2 \pm 14.4$ & 0.461 \\
Sex (M/F) & $18 / 8$ & $16 / 10$ & 0.771 \\
Weight $(\mathrm{kg})$ & $66.8 \pm 11.2$ & $66.3 \pm 10.3$ & 0.858 \\
Height $(\mathrm{cm})$ & $165.6 \pm 9.4$ & $165.5 \pm 9.4$ & 0.958 \\
Duration of BPB procedure (min) & $14.4 \pm 4.6$ & $14.1 \pm 3.1$ & 0.820 \\
Duration of anesthesia (min) & $119.8 \pm 29.2$ & $105.6 \pm 27.1$ & 0.075 \\
Duration of surgery (min) & $68.3 \pm 26.5$ & $56.7 \pm 23.9$ & 0.105 \\
Intravenous fluid (ml/kg/h) & $4.9 \pm 1.5$ & $4.9 \pm 1.4$ & 0.965 \\
Irrigation fluid $(\mathrm{L})$ & $23.7 \pm 11.3$ & $18.9 \pm 10.7$ & 0.122 \\
OR temperature $\left({ }^{\circ} \mathrm{C}\right)$ & $21.2 \pm 1.6$ & $20.8 \pm 1.4$ & 0.367 \\
\hline
\end{tabular}

Values are presented as mean \pm SD or number of patients. Group C: patients were covered with warm cotton blanket during interscalene brachial plexus block, Group F: patients were warmed by forced-air warming during interscalene brachial plexus block. OR: operation room. 
Table 2. Perioperative Temperature and Incidence of Intraoperative and Postoperative Hypothermia

\begin{tabular}{|c|c|c|c|}
\hline Variable & Group C $(n=26)$ & Group $F(n=26)$ & P value \\
\hline Temperature on arrival at $\mathrm{OR}\left({ }^{\circ} \mathrm{C}\right)$ & $36.6 \pm 0.4$ & $36.8 \pm 0.4$ & 0.156 \\
\hline \multicolumn{4}{|l|}{ Intraoperative period } \\
\hline Normothermia $\left(\geq 36.0^{\circ} \mathrm{C}\right)$ & $1(3.8)$ & $11(42.3)$ & 0.003 \\
\hline Hypothermia $\left(<36.0^{\circ} \mathrm{C}\right)$ & $25(96.2)$ & $15(57.7)$ & \\
\hline Severity of hypothermia & & & 0.239 \\
\hline Mild $\left(35.5-35.9^{\circ} \mathrm{C}\right)$ & $13(52)$ & $12(80)$ & \\
\hline Moderate $\left(35.0-35.4^{\circ} \mathrm{C}\right)$ & $10(40)$ & $3(20)$ & \\
\hline Severe $\left(34.5-34.9^{\circ} \mathrm{C}\right)$ & $2(8)$ & $0(0)$ & \\
\hline Temperature on arrival at PACU $\left({ }^{\circ} \mathrm{C}\right)$ & $35.6 \pm 0.4$ & $36.1 \pm 0.4$ & $<0.001$ \\
\hline Normothermia $\left(\geq 36.0^{\circ} \mathrm{C}\right)$ in PACU & $8(30.8)$ & $17(65.4)$ & 0.026 \\
\hline Hypothermia $\left(<36.0^{\circ} \mathrm{C}\right)$ in PACU & $18(69.2)$ & $9(34.6)$ & \\
\hline Thermal comfort scale (no cold/moderate/unbearable) & $19 / 7 / 0$ & $21 / 5 / 0$ & 0.743 \\
\hline Postoperative pain in PACU (no pain/mild/moderate/severe) & $23 / 3 / 0 / 0$ & $22 / 4 / 0 / 0$ & $>0.999$ \\
\hline
\end{tabular}

Values are presented as mean \pm SD or number of patients (\%). Group C: patients were covered with warm cotton blanket during interscalene brachial plexus block, Group F: patients were warmed by forced-air warming during interscalene brachial plexus block. OR: operation room, PACU: post-anesthetic care unit, Thermal comfort scale: Thermal comfort scale was evaluated on arrival at PACU, Postoperative pain in PACU: NRS (numeric rating scale) was checked on arrival at PACU, Mild: NRS 1-3, Moderate: NRS 4-6, Severe: NRS 7-10.

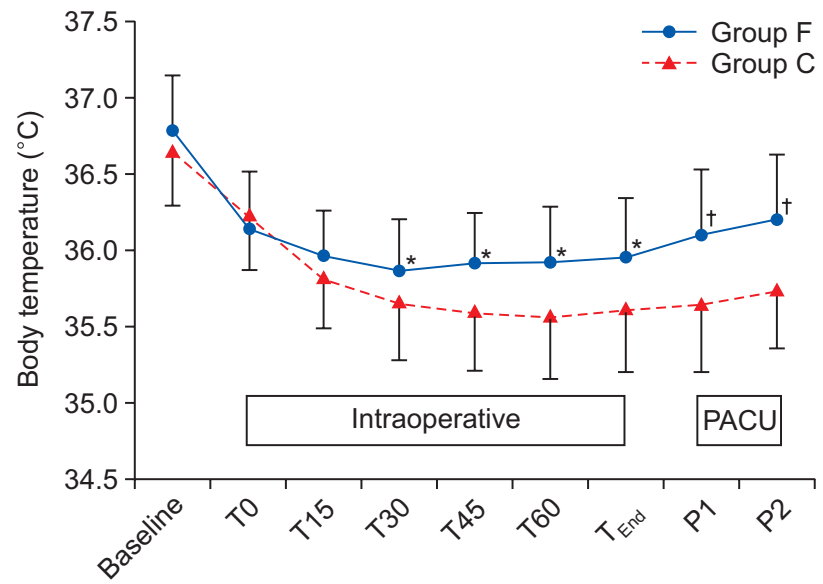

Fig. 2. Intraoperative and postoperative temperatures $\left({ }^{\circ} \mathrm{C}\right)$. Error bars indicate SD of temperature readings at each time. Baseline: Temperature upon arrival at the operation room, T0-60: Temperature immediately to $60 \mathrm{~min}$ after induction of general anesthesia (checked every 15 minutes), $\mathrm{T}_{\text {End: }}$ : Temperature at the end of surgery, $\mathrm{P} 1$ : Temperature upon arrival at post-anesthetic care unit (PACU), P2: Temperature at $30 \mathrm{~min}$ after admission to PACU. Body temperatures were measured by esophageal thermometer intraoperatively and by tympanic thermometer at baseline and in PACU. There were significant differences in perioperative body temperatures between two groups ( ${ }^{*} P<0.05,{ }^{\dagger} P<0.001$, compared with group $C$ ).

using a forced-air warming device during ISBPB procedure in arthroscopic shoulder surgery had beneficial effect on perioperative hypothermia. Characteristic pattern of decrease in temperature under general anesthesia is divided into three phases. The first phase shows rapid decrease in temperature due to core-to-peripheral redistribution of body heat within 1 hour after induction of general anesthesia. In the second phase, a slow and linear fashion of decrease will occur for 2 to 4 hours simply due to heat loss exceeding metabolic heat production. In the third phase, core temperature will reach a plateau and remain constantly until the end of the surgery at 3 to 4 hours after the induction of general anesthesia [15].

Vanni et al. [16] have reported that it is as more effective to perform both preoperative and intraoperative warming than intraoperative warming alone during operation. National Institute for Health and Care Excellence clinical guideline 65 recommends prewarming to prevent perioperative hypothermia. However, prewarming it is not routinely performed due to practical restrictions. It is easy to overlook temperature of patient when performing regional anesthesia for postoperative analgesia before induction of general anesthesia. Horn et al. [17] have demonstrated that prewarming for 15 minutes before and after epidural analgesia is effective in preventing perioperative hypothermia. However, prewarming during regional procedure without using additional time has not been reported previously.

There have been some controversial results about optimal duration of prewarming. Although some experiments have 
revealed that 30 minutes of prewarming is needed to gain heat content exceeding the amount of redistribution [14], another study has shown that prewarming for 20 minutes can reduce the risk of perioperative hypothermia [18]. Jo et al. [19] have conducted controlled trial and found that prewarming for 20 minutes cannot reduce the incidence of intraoperative hypothermia. However, it has effect on the severity of hypothermia. Although the duration of prewarming was different among our patients, our results showed that short time (median duration of ISBPB procedure in group F: $14 \mathrm{~min}$, range: 9-23 $\mathrm{min}$ ) of prewarming was effective in preventing perioperative hypothermia. Therefore, it would be important to perform prewarming although the prewarming time during ISBPB procedure before general anesthesia is short. Lim et al. [20] have shown that ISBPB procedure can reduce the risk of perioperative hypothermia caused by anestheticimpaired thermoregulation by decreasing the requirement of general anesthetics. The temperature of our patients could have been higher than that in the study of Lim et al. [20] due to prewarming and intraoperative warming in our study.

As a limitation of our study, there was difference of the duration of ISBPB procedure for each patient. However, the difference between the two groups was not statistically significant. Although temperature of tympanic membrane was measured preoperatively and postoperatively, esophageal temperature was measured only intraoperatively due to restriction of surgical position. Duration of anesthesia and surgery and the amount of irrigation fluids were different between two groups although statistically insignificant. Duration of hypothermia was not recorded because body temperature recovery $\left(>36^{\circ} \mathrm{C}\right)$ in PACU was not evaluated.

The temperature of patients in this study was higher than that in another study [6] regardless of whether relatively large amount of irrigation fluid was used. This might be due to the fact that we used intraoperative forced-air warming for all patients in this study. Further studies are needed to address the effect of the amount of irrigation fluid on temperature of patients.

In previous studies, warmed irrigation fluid and forced-air warming during surgery have been found to be ineffective in preventing core temperature decrease $[6,12]$. In addition, intraoperative forced-air warming is only effective at 60 minutes after surgery [12]. Therefore, raising peripheral temperature in advance might be meaningful in preventing core temperature decrease due to body heat redistribution.

In conclusion, short-term prewarming using forced-air warming device during ISBPB procedure in arthroscopic shoulder surgery has beneficial effect on perioperative hypothermia.

\section{REFERENCES}

1. Schmied H, Kurz A, Sessler DI, Kozek S, Reiter A. Mild hypothermia increases blood loss and transfusion requirements during total hip arthroplasty. Lancet 1996; 347: 289-92.

2. Flores-Maldonado A, Medina-Escobedo CE, Ríos-Rodríguez HM, Fernández-Domínguez R. Mild perioperative hypothermia and the risk of wound infection. Arch Med Res 2001; 32: 227-31.

3. Frank SM, Fleisher LA, Breslow MJ, Higgins MS, Olson KF, Kelly $\mathrm{S}$, et al. Perioperative maintenance of normothermia reduces the incidence of morbid cardiac events. A randomized clinical trial. JAMA 1997; 277: 1127-34.

4. Heier T, Caldwell JE, Sessler DI, Miller RD. Mild intraoperative hypothermia increases duration of action and spontaneous recovery of vecuronium blockade during nitrous oxide-isoflurane anesthesia in humans. Anesthesiology 1991; 74: 815-9.

5. Chung SH, Lee BS, Yang HJ, Kweon KS, Kim HH, Song J, et al. Effect of preoperative warming during cesarean section under spinal anesthesia. Korean J Anesthesiol 2012; 62: 454-60.

6. Oh JH, Kim JY, Chung SW, Park JS, Kim DH, Kim SH, et al. Warmed irrigation fluid does not decrease perioperative hypothermia during arthroscopic shoulder surgery. Arthroscopy 2014; 30: 159-64.

7. Kim YS, Lee JY, Yang SC, Song JH, Koh HS, Park WK. Comparative study of the influence of room-temperature and warmed fluid irrigation on body temperature in arthroscopic shoulder surgery. Arthroscopy 2009; 25: 24-9.

8. Jo YY, Kim HS, Chang YJ, Yun SY, Kwak HJ. The effect of warmed inspired gases on body temperature during arthroscopic shoulder surgery under general anesthesia. Korean J Anesthesiol 2013; 65: 14-8.

9. Sessler DI, Moayeri A. Skin-surface warming: heat flux and central temperature. Anesthesiology 1990; 73: 218-24.

10. Goldberg ME, Epstein R, Rosenblum F, Larijani GE, Marr A, Lessin J, et al. Do heated humidifiers and heat and moisture exchangers prevent temperature drop during lower abdominal surgery? J Clin Anesth 1992; 4: 16-20.

11. Woolnough M, Allam J, Hemingway C, Cox M, Yentis SM. Intraoperative fluid warming in elective caesarean section: a blinded randomised controlled trial. Int J Obstet Anesth 2009; 18: 346-51.

12. Yoo HS, Park SW, Yi JW, Kwon MI, Rhee YG. The effect of forced- 
air warming during arthroscopic shoulder surgery with general anesthesia. Arthroscopy 2009; 25: 510-4.

13. Forbes SS, Eskicioglu C, Nathens AB, Fenech DS, Laflamme C, McLean RF, et al. Evidence-based guidelines for prevention of perioperative hypothermia. J Am Coll Surg 2009; 209: 492-503.

14. Sessler DI, Schroeder M, Merrifield B, Matsukawa T, Cheng C. Optimal duration and temperature of prewarming. Anesthesiology 1995; 82: 674-81.

15. Sessler DI. Temperature regulation and monitoring. In: Miller's Anesthesia. 8th ed. Edited by Miller RD, Cohen NH, Eriksson LI, Fleisher LA, Wiener-Kronish JP, Young WL: Philadelphia, Churchill Livingstone/Elsevier. 2015, pp 1628-39.

16. Vanni SM, Braz JR, Módolo NS, Amorim RB, Rodrigues GR Jr. Preoperative combined with intraoperative skin-surface warming avoids hypothermia caused by general anesthesia and surgery. J Clin Anesth 2003; 15: 119-25.
17. Horn EP, Bein B, Broch O, Iden T, Böhm R, Latz SK, et al. Warming before and after epidural block before general anaesthesia for major abdominal surgery prevents perioperative hypothermia: a randomised controlled trial. Eur J Anaesthesiol 2016; 33: 334-40.

18. Horn EP, Bein B, Böhm R, Steinfath M, Sahili N, Höcker J. The effect of short time periods of pre-operative warming in the prevention of peri-operative hypothermia. Anaesthesia 2012; 67: 612-7.

19. Jo YY, Chang YJ, Kim YB, Lee S, Kwak HJ. Effect of preoperative forced-air warming on hypothermia in elderly patients undergoing transurethral resection of the prostate. Urol J 2015; 12: 236670.

20. Lim SH, Lee W, Park J, Kim MH, Cho K, Lee JH, et al. Preoperative interscalene brachial plexus block aids in perioperative temperature management during arthroscopic shoulder surgery. Korean J Anesthesiol 2016; 69: 362-7. 